\title{
$\mathrm{COM}$ \\ A textbook linking theory, research, and practice of science communication
}

\section{Reviewed Book}

Reviewed by

\begin{abstract}
\end{abstract}
Keywords

DOI

An overview van Dam, F., de Bakker, L., Dijkstra, A. M. and Jensen, E. A. eds. (2020). SCIENCE COMMUNICATION. AN INTRODUCTION. World SCIENTIFIC SERIES ON SCIENCE COMMUnication: Volume 1. SINGAPORE: WORLD SCIENTIFIC PUBLISHING

\section{Lars Guenther}

This book review will discuss "Science communication. An introduction", edited by Frans van Dam, Liesbeth de Bakker, Anne Dijkstra, and Eric Jensen (2020), the first book in the PCST book series. The review will give an overview, a summary, and a criticism of this textbook, which is intended to be used in educational programs in science communication. As will be outlined, the book puts specific emphasis on linking theory, research, and practice, as well as including more perspectives from developing country contexts, and thus provides a valuable contribution to the dynamic field of science communication.

History of public communication of science; Science and media; Science communication: theory and models

https://doi.org/10.22323/2.19030701

Submitted: 13th April 2020

Accepted: 16th April 2020

Published: 11th May 2020
Educational programs in science communication, such as (online) short courses or $\mathrm{PhD}$ programs are skyrocketing around the world [Trench, 2012; Trench et al., 2014]. Hence, there is a need for up to date and concise reading materials that can be used in these programs. An answer to this need is the book "Science communication. An introduction", edited by Frans van Dam, Liesbeth de Bakker, Anne Dijkstra, and Eric Jensen. This comprehensive overview - 10 chapters on 251 pages - is written by 23 different authors, who try to include perspectives from different countries and regions, with an emphasis to bring in more developing country contexts. The book also aims to better link science communication theory with science communication practice, in particular by highlighting practical examples in text and what the authors call "boxes", i.e., case studies that can stand alone but that are reflected on in the main text. 
The book is the first book in the Public Communication of Science and Technology [PCST] book series and as such was supposed to be launched at the 16th PCST conference in Aberdeen, Scotland. Due to the coronavirus (COVID-19) outbreak, the launch was held online, on April 1, 2020. During this book launch, the editors referred to the recent COVID-19 outbreak, by highlighting that it illustrates a good example for how crucial good communication is. "Doing good science communication is essentially what our book is about", said Frans van Dam. The editors stressed that their book is about how to communicate effectively about science and how to engage people who are not actively engaged in science. While there are many answers to that and many calls to professionalize science communication, the editors identified significant obstacles between research/theory and practice. That is why the book aims to bridge theory and practice, reflected in the entire book - but also in each of the chapters.

At the online book launch, Marina Joubert, one of the reviewers of and contributors to the book emphasized two reasons why this book is an essential extension to the field. Firstly, the editors intentionally added international perspectives, with a specific effort to include issues, challenges, and case studies from the developing world, making the book more pertinent, not only to students in the developing world, but also to those in developed countries, who want to gain a broader and richer perspective of science communication, and the interplay between global and local contexts. Secondly, the book connects science communication theory and practice clearly and accessibly.

Currently, the book is available as hardcover and e-book. A softbound version should follow soon.

As highlighted in the first chapter ("Setting the scene"), the book is supposed to be a starting point - an overview - to better understand what is known about science communication in theory and in practice. The first chapter gives definitions, provides the historical background, and discusses global developments in science communication, its content, its people, and its means. Following, three chapters focus in more detail on the field of science communication, five chapters introduce sub-disciplines of science communication, and the last chapter deals with research and evaluation in science communication. In sum, the book reflects on a variety of topics that mirror the complexity of science communication.

The three chapters focusing on the field of science communication bring together the views of science (including scientific research and scientific knowledge), the process of communicating science, and science in dialogue. They systematically provide essential reflections and explanations of the philosophy of science (from a Western world perspective); science communication actor's interests, goals, and motives; communication models; and public participation in science. In all chapters, the dynamics of the field are emphasized and current trends in science communication are explained.

These trends are also reflected upon in the five chapters on the sub-disciplines of science communication. The individual chapters focus on informal science education, science journalism, risk communication, health communication, and environmental communication. The chapters provide definitions, characteristics, 
and examples; they are up to date introductory chapters, touching on the basics of theory and practice and in most cases point to further references.

The last chapter deals with research in science communication; it explains the social scientific research process, common research methods, and research ethics. Such a chapter delivers important basics, especially since many students in educational programs of science communication do not have a social scientific background. The chapter also raises further research questions and by introducing them actually touches upon the many different topics that were dealt with in the entire book.

\section{A criticism}

The book provides a concise, informative, comprehensive, and current overview of key issues in the field of science communication, the background of science communication, its theoretical bases, and its links to science communication practice. Especially the link between theory/research and practice is very well developed in the book and in the individual chapters. I think that is valuable for both readers new to the field of science communication, but also for those who identify with only one of these sides.

I applaud the editors for trying to incorporate perspectives from the developing world. The three reviewers of this book are based at institutions in China, Mexico, and South Africa, as highlighted in the foreword of the book. Many examples provided in the main text are from the developing world, and they give interesting insights; for instance, pseudoscience in South Africa, an environmental campaign parade in Colombia, or a travelling exhibition on the risks of active volcanos in Mexico. Nevertheless, from 23 authors, more than half of them are affiliated with institutions in the Netherlands, and the examples from the Netherlands (and more broadly from the Western World) clearly dominate in the book. One reason for that might be that the book evolved out of a Dutch textbook, which was broadened to include international perspectives, widening its scope and relevance. An idea for future textbooks might be to link authors from developed and developing countries to work together on single chapters [Guenther and Joubert, 2017].

If the editors would want to extend the book and work on a second edition, I think that a broader perspective on internal science communication (i.e., communication within the realm of science, also including informal exchanges between scientists) and the audiences of science communication could be relevant additions. The current book has a strong focus on external science communication. At the same time, related to my remark about audiences of science communication, there could be a reflection on the many surveys of public perceptions of science and technology and recent approaches, such as audience segmentation [e.g., Schäfer et al., 2018]. Actually, the international discussions of results of public surveys in the context of the recent COVID-19 outbreak among members of the PCST and beyond are a good example for how important these surveys are and could be a useful starting point for such a chapter.

Lastly, a textbook is supposed to be an introduction and it can only briefly reflect on the many topics of an active field, such as science communication. The editors and authors of this book do a good job in doing that; however, for some chapters, they could have guided readers better to further sources. An idea would be to provide a list of key publications at the end of each chapter. 
Despite my minor criticism, "Science communication. An introduction" is indeed a comprehensive and concise overview, convincing in its aim to link theory, research, and practice and I will definitely use it for my lectures on science communication. There are more books to follow in the book series and I am convinced that this will be a valuable extension the field of science communication.

References

Guenther, L. and Joubert, M. (2017). 'Science communication as a field of research: identifying trends, challenges and gaps by analysing research papers'. JCOM 16 (02), A02. https://doi .org/10.22323/2.16020202.

Schäfer, M. S., Füchslin, T., Metag, J., Kristiansen, S. and Rauchfleisch, A. (2018). 'The different audiences of science communication: a segmentation analysis of the Swiss population's perceptions of science and their information and media use patterns'. Public Understanding of Science 27 (7), pp. 836-856. https://doi.org/10.1177/0963662517752886.

Trench, B., Bucchi, M., Amin, L., Cakmackci, G., Falade, B., Olesk, A. and Polino, C. (2014). 'Global spread of science communication: institutions and practices across continents'. In: Routledge Handbook of Public Communication of Science and Technology. Ed. by M. Bucchi and B. Trench. 2nd ed. London, U.K. and New York, U.S.A.: Routledge, pp. 214-230. https://doi.org/10.4324/9780203483794.

Trench, B. (2012). 'Vital and Vulnerable: Science Communication as a University Subject'. In: Science Communication in the World. Ed. by B. Schiele, M. Claessens and S. Shi. Dordrecht, Netherlands: Springer, pp. 241-257. https://doi.org/10.1007/978-94-007-4279-6_16.

Author

Lars Guenther is Senior Research Associate in the Cluster of Excellence on "Climate, Climatic Change, and Society" (CliCCS) at University of Hamburg, funded by the German Research Foundation (DFG), and Extraordinary Senior Lecturer at the Centre for Research on Evaluation, Science and Technology (CREST) at Stellenbosch University in South Africa. He obtained his PhD in 2015 at Friedrich Schiller University Jena, Germany, where he worked in DFG-funded projects within the Special Priority Program "Science and the Public". He is interested into public perceptions of (controversial) science, science and health journalism, as well as the public communication about risks and scientific (un)certainty. E-mail: lars.guenther@uni-hamburg.de.

\section{How to cite}

Guenther, L. (2020). 'A textbook linking theory, research, and practice of science communication'. JCOM 19 (03), R01. https:/ / doi.org/10.22323/2.19030701. 